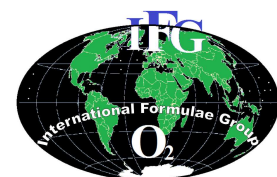

Review

\title{
Microalgae as a source of biofuels
}

\author{
Francis OFFOR IFEANYI $^{1 *}$, Richard CHUKWUEMEKA EHIRI ${ }^{1,2}$, \\ Chihurumnnaya OLA UDE ${ }^{2}$ and Margrett TEMITAYO AKEREWUSI ${ }^{3}$ \\ ${ }^{I}$ Department of Chemistry/Biochemistry, Faculty of Science and Technology, Federal University, \\ Ndufu Alike, Ikwo, P.M.B. 1010, Abakaliki, Ebonyi State, Nigeria. \\ ${ }^{2}$ Department of Industrial Chemistry, Faculty of Physical Sciences, Ebonyi State University, \\ P.M.B. 053, Abakaliki, Ebonyi State, Nigeria. \\ ${ }^{3}$ Department of Microbiology/Biotechnology, Faculty of Science and Technology, Federal University, \\ Ndufu Alike, Ikwo, P.M.B. 1010, Abakaliki, Ebonyi State, Nigeria. \\ *Corresponding author, E-mail: offorifeanyi@gmail.com; Tel: +2348063280098.
}

\begin{abstract}
A number of bio-feedstocks are currently being experimented for biodiesel production and usage. Algal biomass has emerged as one of the most promising sources of biodiesel production. Although research into algae as a potential source of biodiesel is not new, the current oil crises and fast depleting fossil oil reserves have made it more imperative for organizations and countries to invest more time and efforts into research on suitable renewable energy options such as algal oil. Algal fuel as a viable alternative to traditional fuel (diesel) is renewable, carbon neutral, economically sustainable and environmentally friendly. Algal oil can be extracted with methanol via transesterification reaction in the presence of a catalyst to yield biodiesel. The biodiesel produced can be used as jet fuel and as source of fuel in other transportation systems. Finally, since algal oil is non-edible, it does not compromise edible oil which is for human consumption thus, erasing the food versus fuel debate. An attempt is made to review the potential and prospects of microalgae as a sustainable energy provider, thus, providing a stimulus to initiate more research in this area.

() 2014 International Formulae Group. All rights reserved.
\end{abstract}

Keywords: Biodiesel, algae, transesterification, renewable feedstock.

\section{INTRODUCTION}

Algae refer to a group of eukaryotic organisms that belongs to the phylum protista (Evianna, 2008). They are found in diverse environments (fresh water, sea water and saline water) and lack the complex cell structure of higher plants (Schenk et al., 2008). Algae include both microscopic unicellular and macroscopic multicellular organisms which differ from land plants due to the fact that they lack an organized vascular system and they have relatively simple reproductive procedures. All algae are primarily made of proteins, carbohydrates, fats and nucleic acids in varying proportions. While the percentages can vary with the type of algae, some types of algae are made up of $40 \%$ fatty acids based on their overall mass. It 
is these fatty acids that can be extracted and converted into biodiesel (Hayhurst, 2009).

Even before the advent of petroleum, the progenitors of marine microorganisms already existed in nature. Thus, over time, algae had been able to evolve an efficient system of capturing limitless solar energy through photosynthesis (Beer et al., 2009). These microorganisms then use light energy to convert $\mathrm{CO}_{2}$ and $\mathrm{H}_{2} \mathrm{O}$ into carbohydrates and other cellular products, releasing oxygen in the process. Declining petroleum resources and global warming issues has drawn the world's attention to advancing the ability of algae as a potential transport fuel substitute. Mass culture of microalgae has been utilized for more than half a century as potential sources of many useful products like biofuels, human food supplements, aquaculture feeds and pharmaceuticals (Zhang et al., 2002; Samira et al., 2011). Numerous studies on microalgae culture, technology and applications has also been done in the past (Kalita, 2008; Saxena et al., 2009; Khan et al., 2009, Qiang et al., 2008).

Algae grown in ponds can be far more efficient than higher plants in capturing solar energy especially when grown in bioreactors (Gross, 2009). If algal production can be scaled up to industrial capacity, less than 6 million hectares would be needed globally to meet the current fuel demand (Guschina and Harwood, 2006). This consists of less than $0.4 \%$ of arable land which would be an achievable goal from global agriculture.

There are a number of algal species that are being studied for their suitability as crops for mass oil production. Table 1 gives a list of these species.

The objective of this study is to review Algae that are of great interest in the production of biodiesel due to the fact that a number of species of fresh water and marine algae contain large amounts of high quality polyunsaturated fatty acids which can be produced for aquaculture operations (Hayhurst, 2009). Algae can grow heterotrophically on cheap organic substrates without light and under well controlled cultivation conditions. Several strategies are important when determining ways to increase the use of algae for commercial production of polyunsaturated fatty acids in the near future. These include continuous selection and screening of oleaginous species, improvement of strains using genetic engineering, optimization of the culture conditions and the development of efficient cultivation systems. It is also important to determine whether the polyunsaturated fatty acids are located within the membrane lipids or in the cystol (Gross, 2009). Algae can also produce a large number of different types of lipids which include but are not limited to neutral lipids, polar lipids, esters, sterols, hydrocarbons as well as phenyl derivatives such as tocopherols, carotenoids, terpenes, quinines and phytylated pyrrole derivatives like chlorophylls (Guschina and Harwood, 2006). Chlorophyceae (green algae) are among the highly preferred algal strain for researchers. However, green algae tend to produce starches instead of lipids and require nitrogen to grow. Green algae possess certain advantages over other species such as high growth rates at $30{ }^{\circ} \mathrm{C}$ and high light levels in aqueous solution (Haas, 2005). Bacilliarophya (diatom algae) are also favored by researchers. One drawback to their usage is that the diatom algae require silicon to be present in the growth medium. When algae are grown under nutrient deficient conditions, though the algae produces more oil per weight of algae, the amount of algae produced will however, be reduced. Most algae are tolerant to temperature fluctuations but diatoms have narrow temperature range (Guschina and Harwood, 2006).

The objective of this study is to review the current and future prospects of microalgae as a viable feedstock for biofuel production in order to stimulate the need for more research in this area.

\footnotetext{
Algal fuel

Algal fuel is an alternative to fossil fuel and utilizes algae as its source of natural deposits. Fluctuating oil prices, dwindling arable lands for agriculture and world food
} 
crises have ignited interest in algaculture (algae farming) which involves using land that is not suitable for agriculture (Cornel, 2008).

\section{Lipids from algae}

Microalgae contain lipids and fatty acids as membrane components, metabolites, storage products and sources of energy. Microalgae which include alga strains, diatoms and cyanobacteria have been found to contain high levels of lipids (over 30\%). Due to the high lipid content, these microalgal strains are of great interest in research for sustainable sources for the production of biodiesel. It has been found that algae (in form of algal oil) contains between $2 \%-40 \%$ lipid by weight (Qiang et al., 2008; Ackman et al., 1998). Algal oil has been found to be very high in unsaturated fatty acids such as arachidonic acid, eicospentaenoic acid, docasahexanoic acid, gamma linolenic acid and linoleic acid (Ackman et al., 2008). When comparing the liquid yield of algae to vegetable sources, algae can produce between 20,000 to 100,000 liters per hectare (Basora, 2005).

Lipid accumulation in algae usually occurs during periods of environmental stress including growth under nutrient deficient conditions.

The lipid and fatty acid content of microalgae differ according to the culture conditions. Microalgae are classified as the most primitive form of plants whose photosynthetic behavior is similar to that in higher plants. Due to the fact that cells grow in aqueous suspension; microalgae have more efficient access to water, carbon (IV) oxide and other nutrients. These factors account for the ability of microalgae to produce larger quantities of oil per unit area of the land as compared to terrestrial oil seed crops (Hayhurst, 2009). When algae are grown under optimal conditions, they synthesize fatty acids principally for esterification into glycerol based membrane lipids which make up about $5-20 \%$ of their dry cell weight. Fatty acids include medium $\left(\mathrm{C}_{10}-\mathrm{C}_{14}\right)$, long chain
$\left(\mathrm{C}_{16}-\mathrm{C}_{18}\right)$ and very long chain $\left(>\mathrm{C}_{20}\right)$ fatty acid derivatives.

\section{Cultivation of algae}

Algae can produce up to 300 times more oil per acre than conventional crops such as rapeseed, palms, soybeans, or jatropha. Also, since algae has a harvesting cycle of 110 days, it permits several harvests in a very short time frame thus, making it more economically viable than yearly crops (Chisti, 2007). Algae can also be grown on land that is not suitable for other established crops, for instance, arid land, land with excessively saline soil, and drought-stricken land. This minimizes the issue of taking away pieces of land from the cultivation of food crops (Schenk et al., 2008). Major means of cultivating microalgae include photobioreactor system, closed loop system and open pond system (Becker et al., 1994).

Photobioreactor system of algal culture involves the pumping of nutrient laden water through plastic tubes (called bioreactors) that are exposed to sunlight. In an open pond system (exposed to open air), the major problem is risk of contamination of other organisms blown in by the air whereas in a closed loop system (closed to open air), the major problem is finding a cheap source of sterile $\mathrm{CO}_{2}$.

The difficulties in efficient biodiesel production from algae lie in finding an algal strain with a combination of high lipid content and fast growth rate, ease of harvesting, costeffective cultivation system and access to concentrated $\mathrm{CO}_{2}$ to increase the rate of production (Becker et al., 1994).

\section{Harvesting and extraction of oil from algae}

Concentration of high density algal cultures is typically carried out by concentrating the culture using either chemical flocculation or centrifugation. Chemicals such as $\mathrm{Al}_{2} \mathrm{SO}_{4}$ or $\mathrm{FeCl}_{3}$ are added to cause the cells to coagulate and precipitate at the bottom or float to the surface. Then, the algal biomass is recovered by removing the supernatant fat or skimming the cell off the 
surface. Once this process has taken place, the coagulated algae are no longer suitable as food filter feeders due to increase in particle size (Basora, 2005). A cream separator is then used to centrifuge large volumes of the algal culture. The cells are removed from the centrifuge and reconstituted in a small amount of water which can be stored for 1-2 weeks in the refrigerator. The sample can also be frozen but it must be treated with glucose or dimethylsulfoxide. These chemicals act as protective agents to maintain the integrity of the cell during the freezing process (Basora, 2005). Mechanical methods for extraction of oil from algae include the expeller press and ultrasonic assisted extraction.

In the expeller press method, the algae are dried and the oil pressed out with an oil press. The simplest method for extraction is by mechanical crushing. However, due to the difference in algal strains, a number of different types of press configurations (e.g. screw, expeller and piston) are used. In some cases, chemical extraction methods are combined with mechanical crushing (Basora, 2005; Bebemann et al., 1982). Organic solvents which can be used chemically to extract the oil include benzene, ether and hexane. These chemicals are hazardous and must be treated with care. The hexane solvent extraction method can be used alone or in conjunction with the oil press/expeller method. After the oil has been extracted from the algae, the remaining pulp is then mixed with hexane in order to remove the remaining oil. The hexane and oil are then separated by the use of distillation apparatus. When these two methods are combined, more than $95 \%$ of the total oil present in the algae can be extracted (Bigogno et al., 2002). Another method called soxhlet extraction uses hexane or petroleum ether to remove the oils through a process of repeated washing in special glass ware (Bigogno et al., 2002).

\section{Transesterification (alcoholysis)}

The main reaction for converting oil to biodiesel is called transesterification (Durrett et al., 2008). Transesterification is a reaction between an ester (triglyceride) and alcohol resulting in the replacement of the ester ('OR') group with an alcohol $(\mathrm{OH})$ group. The oil extracted from algae will react with an alcohol in the presence of catalyst, via a process known as transesterification. The simplified form of transesterification reaction is presented in equation 1 :

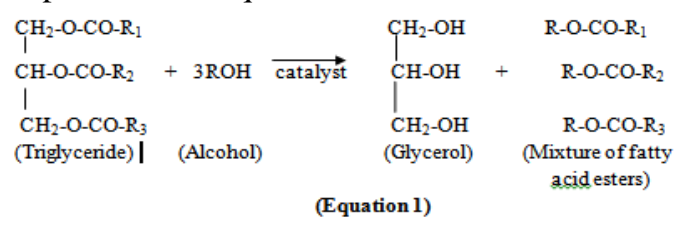

The role of algal genomics and model systems in biodiesel production

Photosynthetic microorganisms have the potential to produce about 8-24 times more lipids per unit area for biodiesel production than the best land plants. Therefore, microbes are in the forefront as future biodiesel producers. The nuclear genomes of only eight algal strains have been sequenced till date. These include: $C$. reinhardtii, $V$. carteri, $C$. merolae, $O$. lucimarinus, O. tauris, A. annophageferrens, $P$. tricornutum and $T$. pseudonana. $C$. reinhardtii is the only organism with extensive genomic, biological and physiological data. For these reasons, Chlamydomonas has become a model eukaryote microbe for the study of many biochemical processes, including photosynthesis, phototaxis, flagellar function, nutrient acquisition and the biosynthesis and functions of lipids (Durrett et al., 2008). Genome sequence and biochemical studies have indicated that Chlamydomonas is an ideal algal species for use as a source of biodiesel. Chlamydomonas has an extensive network of diverse metabolic pathways that can be manipulated using genetic engineering as well as nutrient stress. The advantage of $C$. reinhardtii comes from the fact that it can grow either phototrophically or heterotrophically while maintaining the ability to perform photosynthesis. This allows researchers to study photosynthetic mutations 
that are lethal in other organisms (Durrett et al., 2008).

\section{Potential advantages and challenges of algae as feedstock for biodiesel}

Many algal species have been found to grow rapidly and produce large amounts of triacyl glyceride (TAG). In view of this, it has been postulated that algae could be employed as cell factories to produce cells and other lipids for biofuels and other biomaterials. There are a number of potential advantages of algae as feedstock. Algae can synthesize and accumulate large quantities of neutral lipids (Grossman, 2005). The growth rate of algal species is very high. Some species have 1-3 doublings per day. Algae thrive in saline/brackish water/coastal seawater for which there are few competing demands. Land that is not suitable for conventional agriculture can be used to grow algal species. Algae utilize growth nutrients like nitrogen and phosphorus from a number of wastewater sources which also provides the benefit of wastewater bioremediation. Algae can sequester $\mathrm{CO}_{2}$ from flue gases that are emitted from fossil fuel fired power plants and other sources which reduce the emission of major greenhouse gas. Other by-products including biopolymers, proteins, polysaccharides, pigments, animal feed, fertilizer and hydrogen are value added co-products or by-products that are produced from the growth of algae. Algae can also grow throughout the year with an annual biomass productivity that surpasses that of terrestrial plants by about ten-fold (Collier and Fogg, 1995). Based on the photosynthetic efficiency and the growth potential for algae, theoretical calculations indicate that an annual production of about 200 barrels of algal oil per hectare of land may be achievable from mass algal cultures (Collier and Fogg, 1995). Unfortunately, production of biofuel from algae has not proceeded beyond the small laboratory or field testing stage due to the fact that the lipid yields obtained from algal mass culture had till date been performed at around 10-20 times lower than the theoretical maximum. This fact has historically made algal oil production technology prohibitively expensive (Collier and Fogg, 1995). If the biodiesel is produced from feedstocks that are high in polyunsaturated fatty acids (PUFAs), the fuel will have good cold flow properties, but they are susceptible to oxidation which leads to long term storage problems (Cobelas and Lechado, 1989).

\section{Future of algal feedstock based biodiesel}

Till date, funding has been an issue for full scale development of algae based biofuel technology. In order to fully exploit the potential of algae as a source of biofuels, it is necessary to pioneer new engineering innovations and breakthroughs in algal mass culture as well as downstream processing. However, the most important issue is the need for research on the fundamental biological questions that are related to the regulation of lipid metabolism (Chuecas and Riley, 1999). There are several biological challenges and opportunities. At the biochemical level, it is important to understand the synthetic pathways in algae that are responsible for the production of fatty acid and triacyl glyceride (TAG).

In addition, it is important to understand how algal cells control the flux of photosynthetically fixed carbon and its partitioning into different groups of major macromolecules. It is also necessary to understand the relationship between the cell cycle and TAG accumulation. The isolation and characterization of algae from unique aquatic environments is also necessary in order to provide insights into the unique mechanisms that algae possess for more efficient lipid production. Metabolic engineering through the use of genetic manipulation should be undertaken in order to optimize the production of algal oils. Large scale culture systems must be designed in order to allow for the maximum yield of lipids from algal strains. Ways to reduce the cost and energy consumption associated with the 
processing of algal biomass must also be explored. Methods for efficient lipid extraction from algal biomass must be designed in order to make the process feasible (Chuecas and Riley, 1999).

\section{Enhancement of economic feasibility of} biodiesel from microalgae

As shown in Table 2, there are a number of high value bio-products that can be extracted from algae. One possible method of increasing the economic feasibility of microalgal biofuel production is to coproduce high value products along with the biofuel. This would conceptually involve sequentially cultivating algae in a farming facility to mitigate $\mathrm{CO}_{2}$ levels, extracting bio-reactive products from the harvested algal biomass, thermally processing the biomass in order to extract high value chemicals and then processing the biofuel for different applications. This has the potential to significantly enhance the cost effectiveness of algal biofuel production (Guschina and Harwood, 2006).

Table 1: Algae strains currently being studied globally.

\begin{tabular}{l}
\hline Neochloris Oleabundans \\
\hline Scenedesmus Dimorphus \\
Euglena Gracillis \\
Phaeodactylum Triconutum \\
Pleurochrysis Carteraee \\
Pyrmnesium Parvum \\
Tetraselmis Chui \\
Tetraselmis Suecica \\
Isochrysis Galbana \\
Botrycoccus Braunii \\
\hline
\end{tabular}

Table 2: Some high-value bio-products extracted from microalgae.

\begin{tabular}{|c|c|c|}
\hline Product Group & Applications & Examples (Producer) \\
\hline $\begin{array}{l}\text { Phycobiliproteins } \\
\text { carotenoids }\end{array}$ & $\begin{array}{l}\text { Pigments, } \\
\text { cosmetics, } \\
\text { provitamins } \\
\text { pigmentation }\end{array}$ & $\begin{array}{l}\text { Phycoyanin (Spirulina platensis), beta } \\
\text { carotene (Dunalieella salina), astaxanthin } \\
\text { and leutin (Haematococcus pluvialis) }\end{array}$ \\
\hline $\begin{array}{l}\text { Polyunsaturated fatty acids } \\
\text { (PUFAs) }\end{array}$ & $\begin{array}{l}\text { Food additive, } \\
\text { nutraceutics }\end{array}$ & $\begin{array}{c}\text { Eicosapentaenoic acid (EPA) } \\
\text { (Chlorellaminutissima), docasahexaenoic } \\
\text { acid (DHA) (Schizochytrium sp.), } \\
\text { Arachidonic acid (AA) (Parietochlorisincise) }\end{array}$ \\
\hline Vitamins & Nutrition & $\begin{array}{l}\text { Biotin (Euglena gracilis), } \dot{\alpha} \text {-tocopherol } \\
\text { (Vitamin E) (Euglena gracilisa), ascorbic } \\
\text { acid (Vitamin C) (Prototheca moriformis) }\end{array}$ \\
\hline
\end{tabular}




\section{REFERENCES}

Ackman RG, Tocher CS, McLachlan J. 1998. Marine phytoplankter fatty acids. $J$. of Fish. Res. Board Canada, 25: 1603-1620.

Basora MM. 2005. Fatty acid composition of lipids in microalgae. Int. J. Algae, 7: 3357.

Bebemann JR, Goebel RP, Welssman JC, Augustein DC. 1982. Microalgae as a source of ligand fuels. Final Technical Report to US Department of Energy, Washington DC: 102-107.

Becker EW. 1994. Microalgae: Biotechnology and Microbiology. University Press: NY, Cambridge; 178.

Beer LL, Boyd ES, Peters JW, Posewitz MC. 2009. Engineering algae for biohydrogen and biofuel production. Curr. Opin. Biotechnol., 20(3): 264-271.

Bigogno C, Khozin-Goldberg I, Boussiba S, Vonshak A, Cohen Z. 2002. Lipid and fatty acid composition of the green oleaginous alga, Parietochloris incisa, the richest plant source of arachiodinic acid. Phytochem., 60(5): 497-503.

Chisti Y. 2007. Biodiesel from microalgae. Biotechnol. Adv., 25: 294-306.

Chuecas I, Riley JP. 1999. Component of fatty acids of the total lipid of some marine phytoplankton. J. Mar. Bio. Ass. UK, 49: 97-116.

Cobelas MA, Lechado JZ, 1989. Lipids in Microalgae: A review. J. of Biochem., 40: 118-145.

Collier DM, Fogg GE. 1995. Studies of fat accumulation by algae. J. Exp. Bot., 6: 256-275.

Cornell CB. 2008. First Algae Biodiesel Plant Goes Online: April 1, 2008. Available at: http://gas2.org/2008/03/29/first-algaebiodiesel-plant-goes-online-april-1-2008/.

Durrett T, Benning C, Ohlorrge J. 2008. Plant Triacyl glycerols as feedstock for the production of biofuels. Plant J., 54: 7889.

Eviana H. 2008. A promising oil alternative. Algae Energy Washington, 2: 20-25.
Gross M. 2009. Biofuels: The Next Generation. Edu. Chem., 46(5): 78-80.

Grossman A. 2005. Paths towards algal genomics. Plant Physio., 137: 410-427.

Guschina IA, Harwood JL. 2006. Lipids and Lipid Metabolism in Eukaryotic Algae. Prog. Lipid Res., 45(2): 160-180.

Haas MJ. 2005. Improving the Economies of Biodiesel Production through the use of low value lipids as feedstock. Fuel Process Technol., 86: 1087-1096.

Hayhurst T. 2009. Company to create Biofuel from Algae. Waste and Recycling News, 14(20): 16-17.

Kalita D. 2008. Hydrocarbon plant: new source of energy for future. Renew. Sustain. Energ. Rev., 12(2): 455-471.

Khan SA, Rashmi Hussain MZ, Prasad S, Banerje UC. 2009. Prospects of biodiesel production from microalgae in India. Renew. Sust. Energ. Rev., 13(9): 23612372.

Qiang HI, Sommerfield M, Jarvis E, Ghiardi NJ. 2008. Microalgal triacyl glycerol: Feedstock for biofuel production: Perspectives and Advances. Plant J., 54: 621-626.

Samira C, Bouziane M, Khaled C, Fethia A, Kamel A. 2011. Biohydrogen production using green microalgae as an approach to operate a small proton exchange membrane fuel cell. Int. J. Hydrogen Energ., 36: 4089-4093.

Saxena RC, Adhikari DK, Goyal HB. 2009. Biomass-based energy fuel through biochemical routes: a review. Renew. Sustain. Energ. Rev., 13(1):167-178.

Schenk MP, Thomas-Hall SR, Stephens E, Marx U, Mussgnug JH, Posten C, Kruse O, Hankamer B. 2008. Second generation biofuels: high-efficiency microalgae for biodiesel production. Bioenerg. Res., 1: 20-43.

Zhang X, Zhou B, Zhang Y, Cai Z, Cong W, Ouyang F. 2002. A simple and low-cost air lifts photobioreactor for microalgal mass culture. Biotechnol. Lett., 24: 17671771. 